\title{
A terceira linguagem no cross-cultural marketing
}

\section{The third language in cross-cultural marketing}

DOI: $10.46814 / \operatorname{lajdv3n5-023~}$

Recebimento dos originais: $01 / 05 / 2021$

Aceitação para publicação: 31/06/2021

\section{Renato Rodrigues Martins}

Doutor e pós doutorado

Universidade Estadual de Londrina

Rua Rubens Carlos de Jesus 111, casa 50 Londrina PR CEP: 86055-240

\section{RESUMO}

Aborda a pesquisa de pós-doutoramento do autor, que propõe a terceira linguagem apoiada nas dimensões culturais de Hofstede, uma abordagem da comunicação mercadológica transcultural no século XXI. Nos mercados internacionais a influência cultural determina a gestão estratégica da comunicação persuasiva. As organizações multinacionais brasileiras que atuam nos mercados externos enfrentam a competição que foca suas ações comunicacionais na produção de imagem e em produtos de valor. A terceira linguagem, ao incorporar a comunicação transcultural, pode ser utilizada como um diferencial competitivo das organizações brasileiras internacionais.

Palavras-chave: Terceira linguagem; Hofstede; transculturalidade; mercado; responsabilidade.

\begin{abstract}
Addresses the author's post-doctoral research, which proposes the third language supported by Hofstede's cultural dimensions, an approach to cross-cultural marketing communication in the $21 \mathrm{st}$ century. In international markets, cultural influence determines the strategic management of persuasive communication. Brazilian multinational organizations that operate in foreign markets face competition that focuses their communication actions on image production and value products. The third language, by incorporating cross-cultural communication, can be used as a competitive differential of Brazilian international organizations.
\end{abstract}

Keywords: Third language; Hofstede; transculturality; market; responsibility.

\section{INTRODUÇÃO}

Este artigo objetiva discutir as práticas da comunicação persuasiva transcultural, integrando os fundamentos da terceira linguagem aos das dimensões culturais de Hofstede e mostrar como as organizações transnacionais podem adotar a terceira linguagem na sua gestão da comunicação transcultural. Nesta abordagem da terceira linguagem o autor está empenhado em investigar como as empresas multinacionais brasileiras - as chamadas novas entrantes - podem utilizar tal comunicação no mercado internacional, agregando valor e competitividade a sua gestão. 
A visão transcultural da terceira linguagem surge da necessidade de aplicar o referencial teórico e conceitual da comunicação mercadológica, em ambientes tão díspares como existentes no mercado brasileiro. Para auxiliar a comunicação em âmbito internacional e com ferramental teórico próprio, a terceira linguagem é apresentada agora para responder à seguinte pergunta: É possível desenvolver uma abordagem comunicacional transcultural a partir das dimensões culturais de Hofstede.

Este tema é debatido a partir da comunicação entre a organização e os seus públicos, angariando reputação e resultados quantificáveis. A terceira linguagem busca ainda os resultados do marketing transcultural ético, responsável e sustentável. Chama-se "terceira" porque propõe a integração de duas visões (a primeira é a da propaganda - persuasiva - e a segunda é a de relações públicas - institucional), pois cada uma das linguagens, isoladas, é capaz de absorver os conceitos propostos por Hofstede, mas a terceira linguagem, como concebida, seria mais apta para esse propósito.

Todas essas demandas devem ser investigadas num contexto em que a interculturalidade - a conexão entre culturas - marca um novo mundo, e a diferença não é mais o que distancia, e sim o que aproxima, a ligação entre pessoas de nacionalidades e costumes diferentes. A terceira linguagem é, assim, uma forma de comunicação persuasiva que pode ajudar a gerir a diversidade cultural nas organizações, tornando-as mais competitivas.

As organizações buscam formas mais eficientes e duradouras para comunicar, interna e externamente nas organizações. O marketing das organizações aparece em sua versão mais característica de convencimento da satisfação do público, por meio da comunicação persuasiva, e utiliza recursos de sedução, da criação de sentido, sugestões e promessas de uma vida melhor. $\mathrm{Na}$ tercei- ra linguagem, há uma multiplicidade de elementos: o contraste entre o relacionamento puramente comercial e o institucional em um contexto cultural.

Por entender ser possível uma terceira via - a convergência entre esses dois tipos de discursos - a terceira linguagem assume abordagens divergentes, para desvendar uma linha intermediária em que se possa efetuar uma enunciação capaz de colocá-los em sintonia nas questões de gestão da comunicação transcultural. Ou seja, alinhar duas falas aparentemente desiguais para compreender suas limitações e barreiras e equilibrá-las para atuar no seu interior em diferentes contextos culturais.

Assim, a ênfase é o uso da comunicação mercadológica transcultural voltada para a melhoria das relações comerciais na sociedade. Nesse sentido, a terceira linguagem, na gestão do chamado Cross-cultural marketing opera uma nova oportunidade que se abre para aquelas organizações nacionais que atuam - ou que pretendem atuar - no concorrido mercado internacional, tornando-as mais competitivas e minimizando os desafios e as barreiras culturais do exterior.

É nesse contexto que se aplica a terceira linguagem internacional: uma forma criativa, crível, didática, responsável e ética de discurso mercadológico transcultural para criar valor, reputação, cultura 
de consumo responsável e duradouros relacionamentos para as organizações e seus mercados, tornando-as mais competitivas.

\section{OS PRESSUPOSTOS DA TERCEIRA LINGUAGEM}

As modernas sociedades de consumo têm, na comunicação mercadológica, papel dominante, ao educar e valorizar as características sociais e culturais de seus clientes, desenvolvendo mecanismos apropriados para controlar as massas consumidoras, e criar desejos, sonhos e mitos para as marcas. Por sua vez, a comunicação institucional muitas vezes não recebe o devido cré- dito, uma vez que, pela falta de resultados no curto prazo, é entendida como geradora de custos injustificáveis.

O panorama que se apresenta não é apenas brasileiro, visto que existe uma crise, não só da comunicação, mas da ordem econômica mundial, na busca de resultados rápidos a qualquer preço. Assim, os comunicadores têm enormes responsabilidades, já que o marketing e suas ferramentas promocionais sofrem de profunda falta de credibilidade. Na sociedade empresarial contemporânea, a eficácia das transações comerciais é superior à visão institucional e empresas necessitam inventar maneiras de estar na mídia, criando uma marca e seu conceito, surpreendendo sempre.

Está clara a necessidade de rever os conceitos da comunicação mercadológica transcultural, na insustentável fragilidade da criação de mitos e aceitar que a comunicação corporativa estratégica deve pautar-se pela construção dos relacionamentos das organizações com seus públicos. Profissionais de comunicação e de marketing devem rever seus conceitos e propor ações mercadológicas mais saudáveis para as suas organizações, principalmente para o consumidor e para o meio ambiente.

Para falar do marketing, utiliza-se a expressão "primeira linguagem". De inspiração norteamericana, a primeira linguagem é persuasiva e tem respaldo em um conjunto de autores que discutem formas de conquistar e fidelizar - capturar - o consumidor. As relações públicas foram designadas "segunda linguagem", com base nas ciências humanas, e faz referência a modos de ver o consumidor como membro de um determinado público com o qual a organização estabelece e tenta perpetuar relacionamentos saudáveis.

A terceira linguagem cria um conjunto de valores para resolver essas lacunas de forma triádica, para integrar o trato das atividades mercantis e as de relacionamento. Ela não descarta os preceitos e os fundamentos das outras duas, mas complementa-as e expande os seus conceitos. A premissa é não anular os pontos positivos, porém ampliá-los para fazer frente às questões de conflito apontadas. A questão social e ecológica, a responsabilidade no consumo e a preocupação com o futuro estão na pauta da terceira linguagem, uma visão estratégica de comunicação mercadológica. 
A terceira linguagem é uma proposta de diálogo entre estas duas linguagens para gerar uma terceira, a qual relativiza ambas sem minimizar os efeitos para os quais são indispensáveis: a de marketing, conquista de mercados, satisfazendo as partes e a outra de relacionamento institucional com os públicos de interesse.

\subsection{OS VETORES DA TERCEIRA LINGUAGEM}

Um conjunto de vetores foi organizado com a finalidade de auxiliar na abordagem de questões e na construção de um referencial teórico para estudo. Ou seja, uma grade com correlações que possibilitem dar corpo aos postulados teórico-práticos da terceira linguagem e problematizar os objetos de estudo. Os vetores são definidos a partir de dois fundamentos: a consciência binária e a comunicação dialógica e diferencial.

Consciência binária é a que define os vetores com recursos de leitura que permitem descobrir ou provocar elementos da mudança pelo choque, um abalo pela via do humor, que propõe transformação de comportamentos, posturas e atitudes e é concretizado na comunicação dialógica e diferencial. Na primeira linguagem, a comunicação é persuasiva e busca o diferencial - nos produtos e percepções das marcas que defende. Consegue ser diferencial, mas não tem o poder do diálogo que deve provocar mudanças.

A segunda linguagem procura estimular uma comunicação bilateral é dialógica, mas as vezes se perde no entrosamento dos objetivos da organização e seus públicos. Sua característica revela-se na manutenção de relacionamentos que busquem a compreensão da organização por parte de seus públicos de interesse. Recorrendo-se a esse raciocínio, deve-se pensar cada vetor da terceira linguagem como um discurso e experimentar outras possibilidades de vivenciar verdades e culturas díspares.

Por comunicação dialógica e diferencial entende-se o ato de construir campanhas que repercutam no desapego; sair do conhecido e procurar o desconhecido, fazer diferença; desestabilizar o receptor com fala dialógica, além do discurso "oficial”; tirá-lo do lugar comum e estimular o desejo de ouvir outras vozes; sair do conforto e partir para o desconforto. A comunicação dialógica e diferencial tem possibilidade de experimentar formas mais expressivas em outras verdades e culturas.

\subsubsection{Vetor educação estética}

O comunicador deve motivar a tomada de consciência do público e sua comunicação adquirir caráter educativo em questões de consumo e na utilização de promover persuasão ao evidenciar uma marca. O profissional de comunicação “educa” públicos com características de estética porque interfere no gosto, nos hábitos, na valorização de coisas e conceitos. Ele apresenta uma visão contextualizada diferente da visão mercadológica, enfrentando as consequências provenientes de sua postura. 


\subsubsection{Vetor mestiçagem}

É a capacidade que o profissional tem de valorizar outras formas de conhecimento, de transitar por várias culturas e incorporar diferentes modos de pensar, agir e criar as formas de expressão. Significa valorizar o hibridismo cultural, as características e os espaços multidisciplinares. Mestiçagem incorpora e desarticula o discurso de marketing. O profissional com atitude de mestiçagem tem capacidade de relacionar diferentes áreas e situações de uma organização com a possibilidade de transferir essa competência para a comunicação. A mestiçagem induz à aplicação de ferramentas da comunicação e da administração em sua área de atuação, entre outras.

\subsubsection{Vetor visão de consequência}

A política de comunicação da organização atende aos pressupostos de uma ética responsável, e novos princípios no pensar e no agir irão moldar a realidade da empresa e da sociedade. É marcante, na organização, a procura do progresso da humanidade sem prejuízo do ambiente. Eleva os relacionamentos éticos, procurando o entendimento com o ambiente em que se está inserido. A visão é expressa com definições conceituais entre o certo e o errado e mostrar que o bem e o mal são de responsabilidade do ser humano. Esta abordagem questiona a falta de limites éticos e de controle da tecnologia, além de outros aspectos éticos. O interesse público está acima dos demais interesses e promove a melhoria dos processos produtivos, reduzindo impactos.

\subsubsection{Vetor visão de mercado}

Consiste em avaliar os mercados, em perceber a atitude aquisitiva do cidadão e em priorizar os objetivos mercadológicos, sendo a ampliação de mercados a meta organizacional o que favorece a criação de uma imagem de marca forte. A preocupação mercadológica extrapola o departa- mento de marketing e é incorporada em todos os aspectos institucionais. A meta é a fidelização - recompra -, em níveis adequados, e cria-se valor para a marca e para os produtos da organização.

Os esforços administrativos são mercadológicos e tratam como prioritários os assuntos relativos ao produto, ao preço, ao ponto de venda e à promoção. A visão de mercado determina a criação de produtos com valor agregado. Neste vetor, marca é, portanto, percepção e como tal, pode ser tudo e servir para tudo. O consumidor deseja a fantasia que a marca provoca, e quanto mais se satisfizer mais valioso será. Por visão de mercado, na terceira linguagem, entende-se priorizar esses valores, para garantir a sobrevivência mercadológica de uma marca sem desconsiderar suas características.

\subsubsection{Vetor adequação}


Consiste em pensar o conceito de erro e em substituí-lo pela ideia de se estar mais, ou me- nos, adequado. A estratégia de comunicação pode não estar adequada e não servir para a ocasião, mas certamente se adequará a outra possibilidade. Nada pode assegurar a consistência de uma política de comunicação em uma empresa. Uma campanha, por exemplo, garante um discurso que pode não condizer com a realidade daquele momento, pode garantir adequação em uma de- terminada situação e não ser tão adequada para outro contexto. A ideia da adequação sobrepõe-se ao conceito de erro.

\section{AS DIMENSÕES CULTURAIS DE HOFSTEDE}

Para o psicólogo e antropólogo Gert Hofstede (1928), a cultura é constituída de juízos tradicionais e de valores que estão intimamente ligados. Em seu livro, Hofstede (1984) criou uma classificação de cultura, baseada em pesquisa com trabalhadores da IBM e identificou cinco dimensões que distinguem e classificam as culturas. Distância do poder, aversão à incerteza, grau de machismo e feminismo, caráter coletivista e individualista e orientação com relação ao tempo são as dimensões culturais, denominadas Modelo Hofstede.

\subsection{DISTÂNCIA DO PODER}

Inteligência, altura, força, riqueza, beleza ou outras características pessoais podem diferenciar as pessoas. As desigualdades, por exemplo, aparecem em qualquer lugar ou grupo social e caracterizam os diferentes níveis de poder. A distância do poder pode ser definida como a medida pela qual os indivíduos de uma determinada sociedade aceitam que o poder não é igualmente distribuído. Essa dimensão tem origem nos valores de uma sociedade e são as pessoas que aceitam que existam, ou não, tais desigualdades.

Características das sociedades em que o poder se mostra pouco distante são: as pessoas se sentem iguais; há ênfase no poder legítimo, não no coercitivo; os superiores e os inferiores são interdependentes. Por sua vez, nas sociedades em que o poder aparenta estar muito distante, percebese que as pessoas se sentem desiguais, o destaque é o poder coercitivo, e os subordinados por faixa etária, status, renda ou outro motivo são dependentes dos superiores e esperam-se deles que obedeçam à escala hierárquica.

\subsection{AVERSÃO À INCERTEZA}

A aversão à incerteza é um traço marcante das culturas e se caracteriza como a medida até onde que indivíduos de uma determinada civilização se sentem ameaçados pela dúvida, por situ- ações imprevisíveis ou desconhecidas, e tentam evitar tais situações. Hofstede (2010) define essa dimensão como grau de intolerância ao imprevisível. Quando uma cultura tolera a incerteza, ou o imprevisível, 
ela possui um grau de aversão reduzido. Quando a aversão à incerteza é alta, as pessoas são mais ansiosas.

Nas culturas afetadas por um alto grau de ansiedade - com aversão a incertezas - as normas que organizam a sociedade são imprescindíveis, claras e muito bem definidas. As pessoas são menos receptíveis às mudanças e as inovações. A comunicação tem características mais formais e as mensagens procuram reduzir o medo da insegurança. Nas culturas pouca afetadas pela aversão a incertezas, as leis são criadas para regular somente o necessário. As pessoas são mais descontraídas, menos ansiosas, mais flexíveis e aceitam melhor o novo, o não-usual. Nas relações de trabalho, as sociedades mais avessas a incerteza criam normas e procedimentos - padronização - para a regulação das atividades. Existe necessidade de regulamentar, mas não existem normas ou procedimentos para o relacionamento humano. No trabalho, as pessoas agem com pressa, não desperdiçam tempo - tempo é dinheiro - a perfeição e a pontualidade são valorizadas. A precisão alemã e os relógios suíços explicam essas características.

\subsection{INDIVIDUALISMO E COLETIVISMO}

A sociedade é mais individualista quando os vínculos entre pessoas são fracos. Elas se preocupam com elas próprias e com sua família; fora isso não há nada relevante. Nas culturas coletivistas as pessoas são mais integradas, desde o nascimento, em núcleos familiares ou sociais aos quais devem proteger e mostrar fidelidade por toda a vida.

Nas culturas individualistas há menor distância do poder, as pessoas têm seus próprios valores e juízos, e as opiniões, os direitos e obrigações são coletivos. A comunicação é de baixo contexto e é usual o "eu" e o "meu". O tempo pessoal é um ativo essencial, a vida pessoal deve ser separada do trabalho e as atividades laborais não podem se misturar com as da vida particular. As decisões são individuais e as pessoas agem sozinhas, sem ser influenciadas pelas demais. O sucesso é consequência do trabalho pessoal e o esforço sempre tem uma recompensa. Trabalhando, o sucesso chegará, é a máxima dessa cultura.

Nas culturas coletivistas, todos pertencem a um grupo e fora dele não se consegue nada. As decisões são tomadas pelo grupo, e é a cultura que irá definir a identidade de cada um. Trabalho e vida particular chegam a se confundir. Colega de trabalho é amigo ou companheiro com o qual se mantêm relações sociais. Nas culturas coletivistas há maior distância do poder e as pessoas estão mais próximas nos seus grupos sociais. O relacionamento é importante e, nas relações de trabalho, são observadas as características morais, a fidelidade e a lealdade. Os homens passam muito tempo no ambiente de trabalho e se concilia o ambiente familiar e o de trabalho. 
$\mathrm{Na}$ área da comunicação promocional, enquanto as culturas individualistas focam suas ações na fidelidade, no tratamento diferenciado do cliente especial, em descontos e promoções, nas culturas coletivistas isso tudo pode ser entendido como deslealdade para com o cliente.

\subsection{MACHISMO E FEMINISMO}

O que caracteriza as culturas masculinas são os valores dos homens, como a ambição, a agressividade, o poder ou o status. Nas culturas predominantemente femininas, os valores são outros, como cuidado, carinho, proteção, doçura, paz, ternura etc. Nas culturas masculinas, os homens dominam o ambiente fora do lar, as mulheres a casa. Espera-se dos homens que sejam ambiciosos e das mulheres, ternas. Os estudantes são ensinados a competir, e notas altas, medalhas ou honra ao mérito são valorizadas. As mulheres estudam para a carreira relacionada a área da saúde. Nas culturas masculinas, predomina a ambição, o sucesso, o progresso, o ganhar mais dinheiro, o trocar de casa, o carro, ou seja, as características são inerentes às da sociedade de consumo. Os fracassos são intoleráveis e a mulher é tratada de forma desfavorável.

Nas culturas masculinas o profissional é avaliado pelo dinheiro que ganha; nas femininas, por sua vez, é medido pela qualidade de vida ou pelos amigos que conquista. Nessa cultura o dinheiro não é o mais importante, mas sim a valorização do humano. No trabalho, a cultura feminina se caracteriza pelo compromisso, pela negociação e acordos.

\subsection{ORIENTAÇÃO EM RELAÇÃO AOS PRAZOS CURTOS E LONGOS}

Para Hofstede, outro importante traço característico das culturas é a dimensão temporal. As culturas podem ser diferenciadas com relação às ações e percepções de curto e longo prazo.

Nas culturas caracterizadas pela expectativa a longo prazo, deve-se trabalhar com obstinação; os resultados chegam, cedo ou tarde, sendo a melhoria de vida uma recompensa pelo trabalho árduo. A poupança é vista como necessária e a segurança e os investimentos são principalmente de longo prazo, como, por exemplo, os imobiliários. As principais virtudes são perseverança e paciência e os valores são trabalho, poupança, moderação, empenho, dever, objetivo, futuro, esforço e virtude.

Nas culturas em que as expectativas se regem pelo curto prazo, existe pouco respeito pelas tradições e buscam-se resultados rápidos. O status social é apreciado e toda a simbologia derivada dessa questão é considerada como importante, seja nos objetos seja na postura do seu detentor. Os bens de consumo, que agregam valor ao seu usuário, são importantes pelo padrão do status que conferem. A poupança não é valorizada nesta cultura, e o endividamento pode significar uma possibilidade de investimento para o futuro. A diversão e o tempo livre são valorizados. 


\section{COMUNICAÇÃO, CULTURA E CONSUMO}

No contexto das organizações, a comunicação é o que mais evidencia as diferenças culturais. A promoção é a forma comunicacional que mais necessita ser adaptada aos costumes locais. Para Hofstede (1991), cultura é um fator determinante na conduta consumidora e deve ser considerada no planejamento da estratégia da comunicação mercadológica.

Em culturas pouco avessas a incertezas, a comunicação é mais precisa e de alto contexto. Nas culturas avessas a incertezas, os textos são mais longos, com uma linguagem carregada e uma comunicação de baixo contexto. Nas culturas em que há pouca distância do poder, a mensagem é pessoal, utiliza-se muito o "você"; naquelas em que o poder se afigura distante, a linguagem é mais contextual ou situacional, não dirigida diretamente a pessoa.

Quando o poder se mostra muito distante, as mensagens são mais estruturadas, sérias e formais e os apresentadores de TV, que necessitam de credibilidade, são mais maduros. As crianças sempre aparecem protegidas por pais ou adultos. Mostra-se respeito às hierarquias sociais, econômicas e políticas. Quando o poder se mostra distante, existe uma clara diferenciação dos papéis, como de mulher, mãe e cozinheira, por exemplo. Nas culturas avessas à incerteza, a comunicação dá destaque á aparência do produto, aos testemunhais com explicações técnicas de especialistas.

Nas culturas em que se dá destaque ao coletivismo, a comunicação é de alto contexto e o sentido de tempo é policrônico, com grupos sociais ou famílias. Os apresentadores de TV são sempre em duplas. Nas culturas masculinas, os principais valores atribuídos aos homens são: agressividade, ambição, status elevado, êxito na vida, poder, dominação, força, luta, ostentação, produtividade e rapidez. Os valores atribuídos à mulher são: proteção, modéstia, confiança, cuidado, consenso, doçura, paz e qualidade de vida. Na comunicação transcultural imagem tem mais valor que palavras.

Consumo e cultura caminham juntos e estão intimamente ligados. Os hábitos de consumo estão condicionados às determinantes culturais de um povo as quais explicam o comportamento do consumidor. As influências internas e externas do indivíduo é o fator principal na conduta consumidora do ser humano. A classe social de uma pessoa, assim como sua família e seu grupo, são fatores preponderantes no seu comportamento. A comunicação mercadológica deve considerar esses fatores diferenciais das culturas para atingir seus objetivos.

Grande (2007) demonstra que a cultura de um povo afeta a personalidade do indivíduo. Para ele, as características psicológicas irão distinguir seu comportamento. Na cultura ocidental, essas características são próprias e se manifestam no individualismo. Na cultura oriental, os indivíduos não podem ser separados uns dos outros, visto que a personalidade é coletiva. Pessoas são interdependentes 
e não individuais. Assim a conduta de cada um é motivada pelo grupo e uma resposta é imputada ao grupo a que pertence, dentro de uma determinada circunstância, que define a postura consumidora.

$\mathrm{Na}$ cultura ocidental, mais individualista, a ênfase comunicacional deve estar nos benefícios intangíveis de uma determinada marca ou produto, como status, sucesso, conquistas pessoais etc. Já na cultura oriental, mais coletivista, dá-se ênfase ao grupo, e os benefícios esperados são coletivos, como o bem-estar, a felicidade, a harmonia. Nas culturas mais individualistas, visa-se a consistência entre as atitudes e os comportamentos. Nas culturas mais coletivas o consumidor se envolve com as marcas, já que busca reconhecimento no grupo, que é o que importa.

As razões que levam o consumidor a uma determinada compra têm a ver com as questões antropológicas da cultura. O status, em determinadas culturas, é fator preponderante para o consumo de bens que exteriorizam luxo, sucesso ou poder. O cuidado com o meio ambiente é outro fator condicionante das características culturais. Em culturas que não aceitam insegurança, questões ambientais ressoam e são relevantes.

Ainda conforme Grande (2007), no que se refere à pureza dos produtos consumidos, existem diferenças culturais no consumo. Nas culturas com elevada aversão à incerteza busca-se consumir produtos alimentícios mais puros. Culturas individualistas, orientadas ao curto prazo e com baixa aversão à incerteza aceitam melhor produtos que prometem conforto e comodidade, ao passo que, nas culturas coletivistas, com alta aversão à incerteza e orientadas ao longo prazo, essa realidade não se aplica.

O estado emocional é uma das principais causas de consumo do ser humano na atualidade, mas destacam-se também o status, a diversão, a socialização, entre outros. As culturas, em que os comportamentos são mais coletivos, têm maior tendência para a compra. Nas culturas mais individualistas, nas quais os problemas emocionais são mais gerais, a compra tem como causa preponderante motivos emocionais e afetivos.

Nas culturas caracterizadas por aversão à incerteza, e em que pessoas são muito metódicas e atentas aos detalhes, as compras são mais planejadas. Nessas culturas, as compras por impulso quase não ocorrem, assim como as compulsivas. Já nas culturas com baixo índice de aversão à incerteza, as compras por impulso são mais frequentes.

Segundo Hofstede (1991), nas culturas coletivistas a comida tem função simbólica e social, o que não existe nas individualistas. A água mineral, por exemplo, tem maior consumo nas culturas com alto grau de aversão à incerteza. França, Bélgica, Alemanha e Itália são os países com maior grau de aversão à incerteza e os principais mercados de água mineral.

Quanto mais alta a aversão à incerteza, maior o consumo de carros novos, contrariamente nas sociedades com menor aversão à incerteza, menos é o excesso de carros usados. As culturas mais 
femininas dão mais valor aos carros de maior segurança, conforto e funcionalidade, pois são produtos direcionados às famílias. Nas culturas mais masculinas, destacam-se a aparência e as características técnicas, como potência, velocidade, equipamentos e tamanho, por exemplo.

A religião também é um fator cultural que afeta as políticas de preços das mercadorias. Os países protestantes são de culturas mais severas no que se refere a qualidade, durabilidade e preços dos produtos. Por serem mais rigorosos e não praticarem a ostentação, as mercadorias devem ter mais qualidade. O Norte da Europa é um exemplo da alta qualidade dos produtos.

\section{CONCLUSÕES}

As organizações brasileiras que operam no exterior enfrentam condições distintas do seu mercado de origem, o que cria grande competição entre os participantes. A cultura afeta os ambientes e as arenas de negócios, interferindo nas preferências, nos gostos, nos comportamentos e nas escolhas dos consumidores. As pessoas pensam e se comportam de diferentes maneiras e esses fatores devem ser considerados para se definir as estratégias de comunicação.

Assim, é possível e benéfica a convergência entre as culturas, pois elas não se excluem e a terceira linguagem fornece a necessária capacidade de transitar por elas. Parte do desafio do confronto entre naturezas culturais distintas e efetua uma enunciação capaz de colocar o discurso da organização em sintonia com os diferentes mercados, agindo de forma sinérgica para ultrapassar as limitações territoriais e as barreiras culturais.

O que se mostrou nesse artigo foi a possibilidade de diálogo da terceira linguagem com a visão de cultura organizacional de Hofstede, denominados de dimensões culturais. A ideia é que a terceira linguagem se aproprie das características culturais de um povo - ou de um determinado mercado -, a visão de Hofstede, e monitorado pela grade dos vetores acima descrita. Tanto a primeira quanto a segunda linguagem são capazes de, individualmente, absorver seus preceitos, mas a partir dos argumentos apresentados, a terceira linguagem está mais apta. Terceira linguagem é, na realidade, uma maneira de pensar; é um posicionamento conceitual. 


\section{REFERÊNCIAS BIBLIOGRÁFICAS}

https://www.amazon.com.br/terceira-linguagem-cross-cultural-marketing-ebook/dp/B07SQGKRK3 , em 28Agosto 2021

BARBOSA, Lívia. Cultura e empresas. Rio de Janeiro: Jorge Zahar Ed.; 2002. BEHRENS, Alfredo. Cultura e administração nas Américas. São Paulo: Saraiva, 2008.

BUENO, Wilson C. Comunicação Empresarial: teoria e pesquisa. São Paulo: Manole, 2003. DAFT, Richard L. The New Era of Management. Ohio, USA: Thomson, 2006.

FREITAS, Maria Ester de. Cultura Organizacional: evolução e crítica. São Paulo: Thomson Le-arning, 2007.

FREITAS, Sidinéia Gomes. Cultura organizacional e comunicação. In: KUNSCH, Margarida (Org.) Obtendo resultados com relações públicas. São Paulo: Pioneira, 1997.

FREITAS, S. G. Comunicação interna e o diálogo nas organizações. In: Kunsch. M. M. K (org.). Gestão estratégica em comunicação organizacional e relações públicas. 2.ed.São Caetano do Sul, SP: Difusão Editora, 2009.

GRANDE, Ildefonso. Marketing cross-cultural. São Paulo: Thomson Learning, 2007.

HOFSTEDE, G. Culture's consequences: International differences in workrelated values. Beverly Hills: Sage, 1984.

HOFSTEDE, G. Jan/HOFSTEDE, G/MINKOV, M. Cultures and Organizations. 3ed. London: McGraw-Hill, 2010.

KOTLER, Philip. Administração de marketing: a edição do novo milênio. 10ed. São Paulo: Ed. Prentice Hall, 2000.

MARTINS, Renato R. Terceira Linguagem e mediação: da certeza à crise nos relacionamentos de uma organização. Tese de doutoramento. PUC/SP, 2005.

PINHO, J. B. Comunicação em marketing: princípios da comunicação mercadológica. 6 ed. Campinas: Papirus, 2001.

SANTOS, Milton. Por uma outra globalização: do pensamento único à consciência universal. 18a Ed. Rio de Janeiro: Record, 2009.

SCHNEIDER, Susan C. Managing across cultures. 2nd ed. Harlow, England: Pearson Education. 2003.

VASCONCELLOS, Eduardo. Internacionalização Competitiva. São Paulo: ATLAS, 2008. 